\title{
MODIFICATION OF 'SERVPERF' AS A TOOL FOR SERVICE QUALITY EVALUATION: A STUDY IN A TERTIARY CARE HOSPITAL IN BANGALORE
} BONEY PAUL ${ }^{1}$, JOHN VARGHESE THEKKEKARA ${ }^{2} \&$ SABU N.C ${ }^{3}$

Scholar, Department of Hospital Administration, St. John's Medical College, Bangalore

Professor, Department of Hospital Administration, St. John's Medical College, Bangalore

Associate Professor, Department of Hospital Administration, St. John's Medical College, Bangalore

\begin{abstract}
Service quality assessment is one of the major challenges faced by healthcare administrators today. Parasuraman et al. (1988) has defined service quality as "a global judgment or attitude relating to the overall excellence or superiority of the services". The difference between customer expectations regarding a service to be received and perception of the service to be received has been conceptualized as service quality (Parasuraman et.al.1988, Gronroos 2001). Consequently, providing high service quality to customers, offers a firm an opportunity to differentiate itself and gain a competitive advantage in the market (Wang.2003). Especially in healthcare management, the perception of the patient with respect to the perceived service quality is more important compared to the actual quality of service provided by the healthcare providers. This is the basis on which consumers decide on purchase, repurchase and recommendation of service to others (Paul and Anantharaman 2003).
\end{abstract}

KEYWORDS: Quality Assessment, Healthcare \& Hospital Administration

Received: Oct 05, 2020; Accepted: Oct 25, 2020; Published: Dec 07, 2020; Paper Id.: IJBMROCT20205

\section{INTRODUCTION}

Service quality assessment is one of the major challenges faced by healthcare administrators today. Parasuraman et al. (1988) has defined service quality as "a global judgment or attitude relating to the overall excellence or superiority of the services". The difference between customer expectations regarding a service to be received and perception of the service to be received has been conceptualized as service quality (Parasuraman et.al.1988, Gronroos 2001). Consequently, providing high service quality to customers, offers a firm an opportunity to differentiate itself and gain a competitive advantage in the market (Wang.2003). Especially in healthcare management, the perception of the patient with respect to the perceived service quality is more important compared to the actual quality of service provided by the healthcare providers. This is the basis on which consumers decide on purchase, repurchase and recommendation of service to others (Paul and Anantharaman 2003).

Two of the most used models for service quality measurement are the SERVQUAL and SERVPERF. Parasuraman et al. (Parasuraman and Berry 1985, Parasuraman et.al.1988, Parasuraman and Berry 1991) undertook a series of research projects which gave birth to the service quality model "SERVQUAL". Initially, the model was based on 10 dimensions of service quality which was subsequently reduced to 5 dimensions that encompassed the following factors viz.: Tangibles (physical facilities, equipment and appearance of personnel), Reliability (ability to 
perform the services accurately and dependably), Responsiveness (willingness to help customers and provide prompt services), Empathy (caring and individualized attention given to customers, which includes both access to and understanding of the customer needs) and Assurance (providers' knowledge, courtesy and ability to convey trust and confidence).

The SERVQUAL instrument contains 22 pairs of Likert scale questions designed to measure customers' expectation of a service and the customers' perception of a service provided by an organization. To assess a service quality, the gap for each question is calculated based on comparing the perception score with the expectation score. The positive gap score means that customers' expectations are met or exceeded, while the negative score means the opposite.

Combined with some modification or additional operational measurements, the SERVQUAL instruments have been used to gauge service quality in a variety of service industries including, but not limited to: banking (Carlos et.al 2006, Yavas, Bilgin and Shemwell 1997), hotels (Olorunniwo, Hsu and Udo.2006), sport tourism (Koutharis and Alexandris 2005), retails stores (Jones et.al 2005), library setting (Ho and Crowley 2003), government local authority (Wisniewski 2001), education (Arambewela 2006), airlines (Prayag 2007), mobile communications (Lai, Hutchinson, Li and Bai 2007), and web portal (Liao et.al 2011).

Dean (1999) investigated the applicability of a refined SERVQUAL instrument, consisting of 15 statements, in both medical care and health care settings of Australia. The study results revealed a four-factor structure which approximates, in both environments, the dimensions identified by Parasuraman et al. (1988). 'Assurance' and 'empathy' were the most important dimensions in the health care environment, while 'reliability' or 'responsiveness' dimensions came first in the medical care environment.

Frimpong, Nwankwo and Dason (2010) explored patients' satisfaction with access to public and private healthcare centres in London. The results showed that public patients, as opposed to private counterparts, were dissatisfied with the service climate factors. In general, the study concluded that both public and private healthcare users faced major problems in accessing healthcare. Similarly, Baker, Akgun and Assaf (2008) used an adapted SERVQUAL scale to assess patients' attitudes toward health service in Turkey. Data collected from 472 patients revealed that patient perceived scores are higher than their expected scores for ordinary hospitals and lower than their expected scores for higher level hospitals. 'Responsiveness' and 'reliability' dimensions got the lowest expected scores of all dimensions.

Based on the application of a modified SERVQUAL instrument, Choi et al. (2005) found a significant relationship between service quality dimensions and patient satisfaction in the South Korea health care system, in particular, "staff concern" followed by "convenience of the care process" and "physician concern" dimensions are the most determinants of patients' satisfaction. However, Narang (2010) adopted 20- item scale that had been initially developed by Kattan and Hadded (1998), to measure patients' perceptions of health care services in India. The study reveals that the four factors - health personnel practices and conduct, health care delivery, access to services and, above all, adequacy of resources and services - were perceived positively by patients. Pakdil and Harwood (2005) applied SERVQUAL construct for measuring patients' satisfactions in Turkey by calculating the gap between patients' expectations and perceptions. The study found that patients are highly satisfied with all elements of service quality; specifically, "adequate information about their surgery", 'adequate friendliness' and 'courtesy'. Rohini and Mahadevappa (2006) investigated patients' satisfactions of service quality in Bangalore - based hospitals in India. Their data collected from 500 patients revealed that expectations exceeded their perceptions in 22 items of service quality. The 'assurance' dimension got the least negative score in all 
hospitals. In contrast, Sohail (2003) found that patients' perceptions exceeded their expectations for all items of services provided by private hospitals in Malaysia.

\section{SERVQUAL Criticisms:}

Despite the wide application of SERVQUAL, as an instrument for measuring service quality, it has been subjected to several criticisms regarding its conceptual and operational aspects. Parasuraman et al. (Parasumraman et al. 1988, Parasuraman and Berry 1985, Parasuraman, Berry and Zeithaml 1991) proposed SERVQUAL model based on the confirmation/ disconfirmation theory $(\mathrm{SQ}=\mathrm{P}-\mathrm{E})$. Since then, many marketing researchers have argued that neither disconfirmation theory nor expectation scores have any effect on customer satisfaction, (Parasuraman, Berry and Zeithaml 1991, Carman 1990, Cronin Jr. 1994, Teas 1994). Instead, the perception scores (SERVPERF) have been mainly recommended for measuring service quality as it has higher predictive validity of customers' satisfaction, (Cronin Jr. 1992, Babakus and Mangold 1992, Lee, Lee and Yoo 2000, Luk ST, Layton 2004).

The SERVPERF scale developed by Cronin and Taylor (1992) is one of the important variants of the SERVQUAL scale. For, being based on the perception component alone, it is considered a better scale than the SERVQUAL scale. Not only is the scale more efficient in reducing the number of items to be measured by 50 per cent, it has also been empirically found superior to the SERVQUAL scale for being able to explain greater variance in the overall service quality measured by using a single-item scale. This explains the considerable support that has emerged over time in favour of the SERVPERF scale (Babakus and Boller 1992, Bolton and Drew 1991, Gotlieb, Grewal and Brown 1994, Hartline and Ferrell 1996, Woodruff, Cadotte and Jenkins 1983).

Further, Cronin and Taylor (Cronin Jr. 1992, 1994) argued that the domain of service quality is best measured by consumers' long-term perceptions of service-firm superiority or excellence and operationalized by measures of performance. Cronin and Taylor challenged that performance minus expectations as an inappropriate basis for measuring the quality of services. The fundamental basis for this assertion is that a primary distinction between service quality and consumer satisfaction exists based on the necessity for consumers to personally experience a service encounter in the development of consumer satisfaction judgements. These authors suggest that service quality perceptions, as global attitudes, can develop in the absence of personally experiencing a service (e.g., word of mouth, advertising).

Cronin and Taylor (1992) proposed a performance-based scale SERVPERF, a 22-items scale to measure service quality. The service quality construct is best operationalized by measures of service-firm performance (Cronin and Taylor 1992, Babakus E, Boller 1992, Brown, Churchill Jr. and Peter 1993, Boulding et.al 1993). Though the SERVPERF model is more consistent with the literature, it is also found to be plagued by similar limitations as the SERVQUAL scale, i.e. the SERVPERF scale also does not show a five-dimensional factor structure in the industries where it has been applied.

Paul and Anantharaman (2003) compared the two predominant service quality measures SERVQUAL and SERVPERF and applied the study on Periodontists. They concluded that SERVPERF without importance weights appears to be the better model for measurement of service quality among periodontists. Also, when applied in conjunction with the SERVQUAL scale, the SERVPERF measure has outperformed the SERVQUAL scale (Cronin Jr. 1992, Babakus and Boller 1992). Seeing its superiority, even Zeithaml (one among the founders of the SERVQUAL scale) was of the view that their results are incompatible with both the one-dimensional view of expectations and the gap formation for service quality. Instead, he found that perceived quality is directly influenced only by perceptions of performance (Boulding et.al 
1993). This admittance cogently lends a testimony to the superiority of the SERVPERF scale.

The SERVPERF model has not been tested much in the health care industry, though it has proven itself to be reliable in other industries. One of the limitations when SERVPERF model had been put in practice in healthcare industry was the use of convenient sampling and failure to take healthcare providers into consideration. In teaching hospitals, there can be other variables which would significantly impact the service quality of the healthcare providers. Our critical observation was that at least three other variables namely: 'constraints', 'career development' and 'environmental factors' of the providers to be considered in assessment of service quality. We considered one's knowledge of the latest techniques, freedom in performing independently and career status (beginner or well established in profession) of the provider as contributing elements of the variable 'career development'. Constraints due to workload, availability of manpower in the team, policies of the organization and regulations may impact on quality of one's service. There are other relevant points like pressure from the management, organizational culture, relation with fellow members in the team and family constraints which have considerable influence on one's service; we clubbed them all in the variable 'environmental factors'.

Considering the gravity of the missing elements mentioned, we decided to make a study using a modified version of SERVPERF which includes the missing elements also. Hence in this study, an attempt is made to analyse the feasibility of SERVPERF including the role of healthcare providers to assess the quality of patient care and analyse its importance in patient satisfaction, using a more comprehensive tool - a modified SERVPERF. The scope of the study is limited to the application of SERVPERF and its modification in the doctor-patient circle within the spectrum of service quality. The study is done with the presumption that SERVPERF is an established tool for studying the quality of doctors' patient care.

\section{AIMS AND OBJECTIVES}

This study analyses the satisfaction of service quality among patients using SERVPERF and attempts to bring our evidence for proposal to modify SERVPERF. The specific objectives of this study were: (a) To assess the satisfaction of service quality among patients visiting a selected teaching hospital using SERVPERF tool, (b) To study the 'constraints', 'career development' and 'environmental' factors of the clinicians who provided care to the same selected patients, and (c) To bring out evidence for proposal to modify SERVPERF.

\section{RESEARCH METHODOLOGY}

Data for this study was collected from a sample of doctors and also a sample of patients treated by the same doctors. Multistage sampling was applied for doctors who offer OPD services in the study setting. The clinical departments in the hospital were categorized into basic specialties and super-specialties for the purpose of this study. In the first stage, six departments from the specialty category and 4 departments from super-specialty category were taken at random. Doctors selected at random from each department and who consented for this study was taken as the sample for data collection. The interns and junior residents were excluded. Patients who had taken consultation from the corresponding doctors formed the second population of this study. They were taken by systematic sampling technique. Ten patients each from the OPD of the selected doctors were taken as subjects of our study, forming a sample of 140 patients. However, not more than one patient was taken from any OPD on any given date to avoid bias due to situational factors.

Data collection was done by using structured questionnaire administered on the patients with questions based on SERVPERF tool. A structured questionnaire with the variables 'constraints', 'career development' and 'environmental 
factors' was administered on the doctors selected for the study.

\section{Hypotheses:}

Our basic hypothesis for the study was that satisfaction on quality of care is not related to the 'constraints', 'career development' and 'environmental factors' of healthcare providers. Alternatively, the satisfaction on quality of care is directly related to the 'constraints', 'career development' and 'environmental factors' of healthcare providers.

\section{ANALYSIS}

Paired factor comparison was considered as the appropriate methodology to evaluate the association between the factors. The factors of the healthcare service providers considered for the comparison were constraints, career development and environmental factors. The factors affecting service quality specified in the SERVPERF tool used for service quality evaluation are tangibles, reliability, responsiveness, assurance and empathy. The above said factors are considered separately for each of the selected health care service providers. Paired factor comparison method was used to analyse the responses of the patients of the selected doctors with respect to the score for the constraints, career development and environmental factors of each of the doctors separately. For this purpose, the mean values of the modified factors for doctors were compared against the median values of the patients' assessment to overcome skewness in the scores of the patients.

The factors which showed the highest and lowest score from each of the cases were tabulated separately. The pairs that were repeated five or more times were assessed to be having very strong association, the pairs that were repeated four times were considered to be having strong association, the pairs that were repeated three times were considered to be having moderate association, the pairs that were repeated twice were considered to be having weak association and those pairs that were repeated only once were assessed to be having very weak association.

The paired factor comparison analysis of the high scoring variables reveals that the 'Assurance' variable of SERVPERF consisting of constituents relating to staff behaviour, hospital safety, staff courtesy and staff competency is significant in 78.5 percent of the sample population. It is followed by 'Responsiveness' variable comprising of constituents viz. service information, service promptness, helping nature of the staff and staff concern being significant in $28.2 \%$ of the sample population and the 'tangibles' variable comprising of constituents that includes physical facilities, modern equipment, service materials and staff grooming showing significance in $24.4 \%$ of the sample population.

Furthermore, there is consistent association between 'assurance' and 'career development' variable of the modified scale constituting of doctor's knowledge, freedom for personal growth and career status satisfaction. The paired factor comparison also shows significant association between 'assurance' and 'constraint' variable of modified scale comprising of parameters that includes workload schedule, adequacy of manpower, hospital policy and government regulations. The analysis also shows significant association between the variables 'responsiveness' and 'career development'.

The paired factor comparison analysis of the low scoring variables reveals that the 'empathy' variable of the SERVPERF scale comprising of constituents relating to personal and individual attention, patients' best interests, convenience of hospital operating hours and fulfilment of patient specific needs consistently has poor score throughout the sample subjects. 
The study reveals that improving the 'environmental factors' consisting of management pressure, organizational culture, team-work and family commitments will significantly increase the 'empathy' scores. Also, there is strong association between 'empathy' and 'constraint' of the modified scale comprising of workload schedule, adequacy of manpower, hospital policy and government regulations. Consequently, improving the constraint conditions will have a significant increase in empathy scores.

\section{FINDINGS}

Responsiveness and assurance are the two variables of SERVPERF which showed 'good' rating by more than 88.5 percent of respondents followed by reliability at 71.5 percent, tangibles at 63.1 percent of the sample studied. With regard to the variables proposed for modification for doctors, only career development factor has 59.2 percent of the sample population rating it as 'good'. The results of paired factor comparison indicate that there is consistent association between the 'assurance' variable of SERVPERF tool and 'career development' and 'constraint' variable of the modified tool. The analysis also shows significant association between responsiveness variable of SERVPERF tool and career development variable of the modified tool. There is a strong association between empathy factor of SERVPERF tool and constraint as well as environmental factors of the modified tool.

\section{DISCUSSIONS}

Our sample of patients who participated in this study was almost equal men (51.5 percent) and women (48.5 percent). They were in the age of 19 to 70 years; majority ( 81.5 percent) were in the age of 21 to 50 years. Only 27.7 percent of them were unemployed or students, 25.4 percent were self-employed, 40.8 percent were doing private job, only 3.8 percent were in government job, while 2.3 percent were retired hands. A vast majority ( 83.1 per cent) of the sample subjects of patients were from the city, 6.2 per cent of them from outside the city, but from within the state and only 10.8 per cent were from other states.

The study results found that with respect to the SERVPERF factors, responsiveness and assurance factors have the highest number of respondents ( 88.5 percent) rating it under the good category followed by Reliability (71.5 percent), Tangibles (63.1 percent) with the least being Empathy factor (32.3 percent) rated as good. It is found that 45.3 percent of the patients felt that the Empathy factor of the tertiary care hospital was average with 22.3 percent of them even rating them as poor. These findings are to be understood in the context of a large tertiary care teaching hospital which has nearly three thousand daily footfalls in the OPD and they are mostly middle class and lower middle class population.

The study results portray that with regards to the modified factors for healthcare providers, it is found that only career development factor has 59.2 percent of the sample population under the good category whereas constraint factor with 65.3 percent and environmental factor with 86.9 percent of the sample population falls under the average category.

Cronin and Taylor (1992) critically studied the then existed SERVQUAL tool and proposed SERVPERF as a modified and improved tool for assessing service quality. They reduced the number of items on the tool; but remained focus on the customer alone. Paul and Anantharaman (2003) compared the two tools and stated that SERVPERF is relatively better. Our critical questioning of these two tools when applied in healthcare left us with the understanding that in Indian healthcare industry, the variable 'assurance' is not fully understood by the customer while making assessment of it, as comprehended by the proponents. "Assurance' in turn is comprised of 'staff behaviour', 'staff courtesy' and 'staff competency'. In Indian teaching hospitals, the staff behaviour could largely be influenced by the workload, availability of 
fellow team members. These constraints should necessarily be considered while assessing one's service quality in healthcare facilities, particularly teaching hospitals. The hierarchy in the teaching hospitals most often limit a service provider, especially medical professional, to make independent decisions and performance. The phase of career is hence another variable impacting on service quality. Staff grooming and similar aspects considered under the variable 'tangibles' are observed as being regulated by the 'environmental factors' which we comprehended as composed of pressure from the management, organizational culture and relationship fellow members in the team. There are several studies which have proved that Indian doctors and healthcare providers face challenges to their free and quality service due to factors like these stated above.

Our study was with the objective to study the 'constraints', 'career development' and 'environmental factors' of the clinicians who delivered care to patients. We have found that the service quality of the clinicians as assessed by the patients using the SERVPERF variables is having significant relationship with the 'constraints', 'career development' and 'environmental factors' of the clinicians who served them. Nevertheless we have evaluated SERVPERF variables are valid and fitting to assess the service quality of clinicians, our study found the relative variability in the scores of service quality assessment with respect to the change in the 'constraints', 'career development' and 'environmental factors' of the clinicians.

Customer centred assessment would not be fitting to assess the service quality if our proposed provider centred variables are not taken into consideration. Rather, it could be said that the variability in service quality of clinicians could be due to 'constraints', 'career development' and 'environmental factors' which are acting upon them. Hence, a tool devoid of these aspects which are most often beyond the comprehension of the customers will result in partial and biased assessment of the service quality in Indian healthcare settings, especially teaching hospitals. Cronin and Taylor are of opinion that service quality perceptions, as global attitudes, can develop in the absence of personally experiencing a service through word of mouth, advertising or similar other ways. We have assessed that these perceptions are 'ideal' and could be limited by 'constraints', 'career development' and 'environmental factors' in the attempt to deliver the same. SERVPERF has relative advantages when compared with SERVQUAL; but it has not shown due regard to the 'constraints', 'career development' and 'environmental factors' which generally impact upon most of the service providers.

\section{CONCLUSIONS}

The constituent variables of the career development factor have a significant role in affecting the patient care outcomes of the healthcare providers, especially in teaching facilities. There exists a significant relationship between the variables of assurance factor of SERVPERF and career development as well as constraint factor of modified tool. Hence it is proved that alternate hypothesis is accepted here, which is to say that improvement in the variables of the modified scale will lead to significant changes to service quality assessment of the beneficiaries of healthcare providers. Improving the environmental factors and constraints factors of the healthcare providers will significantly increase the empathy scores of patients. Our modification of the SERVPERF tool thus stands valid and applicable in the selected healthcare settings. However our findings need to undergo more empirical studies due to the limitations we had. The majority of the subjects studied were doctors who were in the middle of their career path. This study considered only on the OPD patients and the service delivered to them. A better picture of the reality will be manifested if in-patients are considered as subjects, but only a long-term study can bring out reliable evidences. However, the incorporation of the SERVPERF as a tool for service quality assessment in the Indian healthcare setup is still in the primitive stage. Therefore, it can be considered as a study 
which shows a path for modification of SERVPERF tool in a manner suited to the Indian context.

\section{REFERENCES}

1. Arambewela R, Hall J. (2006).A comparative analysis of international education satisfaction using SERVQUAL. Journal of Services Research. 6(Special):141-63.

2. Agarwal, Vikas, et al. "Clinical profile of headache from a tertiary care center in eastern India." International journal of general medicine and pharmacy (IJGMP) 2.3 (2013): 9-14.

3. Babakus E, Mangold W.G. (1992).Adapting the SERVQUAL scale to hospital services: an empirical investigation. Health services research. 26(6):767.

4. Babakus, E, Boller G.W. (1992). An empirical assessment of the SERVQUAL scale. Journal of Business research. 24(3):25368.

5. Bakar C, Seval Akgün H, Al Assaf AF. (2008). The role of expectations in patient assessments of hospital care: an example from a university hospital network, Turkey. International Journal of Health Care Quality Assurance. 21(4):343-55.

6. Bolton R.N, Drew J.H. (1991) A multistage model of customers' assessments of service quality and value. Journal of consumer research. 17(4):375-84.

7. Boulding W, Kalra A, Staelin R, Zeithaml V.A. (1993) A dynamic process model of service quality: from expectations to behavioral intentions. Journal of marketing research. 30(1):7-27.

8. Borrse, Mrunall Arun, Sanjay Mahadik, and Dhiraj Balwir. "Pseudoexfoliation Syndrome: Clinical Profile and Visual Outcome after Manual Small Incision Cataract Surgery." MVP Journal of Medical Science 6.2 (2020): 195-201.

9. Brown T.J, Churchill (Jr) G.A, Peter J.P. (1993) Improving the measurement of service quality. Journal of retailing. 69(1): $127-40$.

10. Carlos Fandos Roig J, Sanchez Garcia J, Angel Moliner Tena M, Llorens Monzonis J. (2006).Customer perceived value in banking services. International Journal of Bank Marketing. 24(5):266-83.

11. Carman J.M. (1990). Consumer perceptions of service quality: an assessment of the SERVQUAL dimensions. Journal of retailing. 66(1):33-56.

12. Choi KS, Lee H, Kim C, Lee S. (2005) The service quality dimensions and patient satisfaction relationships in South Korea: comparisons across gender, age and types of service. Journal of Services Marketing. 19(3):140-9.

13. Cronin (Jr) J.J, Taylor S.A. (1994). SERVPERF versus SERVQUAL: reconciling performance-based and perceptions-minusexpectations measurement of service quality. Journal of marketing. 58(1):125-31.

14. Cronin (Jr) J.J, Taylor S.A. (1992) Measuring service quality: a re-examination and extension. Journal of marketing. 56(3):55-68.

15. Dean A.M. (1999). The applicability of SERVQUAL in different health care environments. Health Marketing Quarterly. 16(3):1-21.

16. Debbarma, Shibajee, et al. "Epidemiology of Accident Cases Attending a Tertiary Care Hospital in Kanpur." International Journal of Medicine and Pharmaceutical Sciences (IJMPS) 6.1 (2016): 125-130.

17. El-Kattan MH, El-Hadded SA. (1998). Regional Training Course on Mushroom Production, Mushroom Biology and Spawn Production. FAO/UNESCO/ARC/TMF. Cairo. 
18. Gotlieb J.B, Grewal D, Brown S.W. (1994). Consumer satisfaction and perceived quality: complementary or divergent constructs? Journal of applied psychology. 79(6):875.

19. Grönroos, C. (2001).The perceived service quality concept-a mistake? Managing Service Quality: An International Journal. $1 ; 11(3): 150-2$.

20. Ho J, Crowley GH. (2003) User perceptions of the "reliability" of library services at Texas A\&M University: a focus group study. The journal of academic librarianship. 29(2):82-7.

21. Hartline M.D, Ferrell O.C. (1996). The management of customer-contact service employees: an empirical investigation. Journal of marketing. 60(4):52-70.

22. Jones P, Comfort D, Hillier D, Eastwood I. (2005). Retailers and sustainable development in the UK. International Journal of Retail and Distribution Management. 33(3):207-14.

23. Kouthouris. C, Alexandris K. (2005) Can service quality predict customer satisfaction and behavioral intentions in the sport tourism industry? An application of the SERVQUAL model in an outdoors setting. Journal of Sport and Tourism. 10(2):10111 .

24. Kumar, Navneet, Tanu Midha, and Yashwant Kumar Rao. "Determinants of Epilepsy in Children and Adolescents (6-19 Years) in a Tertiary Care Hospital in Kanpur." International Journal of Medicine and Pharmaceutical Science (IJMPS) 8.1 (2018): 53-58.

25. Lai F, Hutchinson J, Li D, Bai C. (2007). An empirical assessment and application of SERVQUAL in mainland China's mobile communications industry. International Journal of Quality and Reliability Management. 24(3):244-62.

26. Liao C, To P.L, Liu C.C, Kuo P.Y, Chuang S.H. (2011). Factors influencing the intended use of web portals. Online Information Review. 35(2):237-54.

27. Lee H, Lee Y, Yoo D. (2000). The determinants of perceived service quality and its relationship with satisfaction. Journal of services marketing. 14(3):217-31.

28. Luk S.T, Layton R. (2004). Managing both outcome and process quality is critical to quality of hotel service. Total Quality Management and Business Excellence. 15(3):259-78.

29. Narang R. (2010). Measuring perceived quality of health care services in India. International journal of health care quality assurance. 23(2):171-86.

30. Olorunniwo F, Hsu M.K, Udo G.J. (2006) Service quality, customer satisfaction, and behavioral intentions in the service factory. Journal of services marketing. 20(1):59-72.

31. Owusu-Frimpong N, Nwankwo S, Dason B. (2010). Measuring service quality and patient satisfaction with access to public and private healthcare delivery. International Journal of Public Sector Management. 23(3):203-20.

32. Pakdil F, Harwood TN. (2005). Patient satisfaction in a preoperative assessment clinic: an analysis using SERVQUAL dimensions. Total Quality Management and Business Excellence. 16(1):15-30.

33. Parasuraman A, Zeithaml V A, Berry L.L. (1988) Servqual: A multiple-item scale for measuring consumer perc. Journal of retailing. 1;64(1):12.

34. Parasuraman A, Berry, L.L (1985). A Conceptual model of service quality and its implications for future research.:41-50.

35. Parasuraman A, Berry L.L, Zeithaml V.A. (1991) Refinement and reassessment of the SERVQUAL scale. Journal of retailing. $22 ; 67(4): 420-51$. 
36. Paul A.K, Anantharaman R.N. (2003) Impact of people management practices on organizational performance: Analysis of a causal model. The International Journal of Human Resource Management. 14(7).1246-1266

37. Prayag G. (2007). Assessing international tourists' perceptions of service quality at Air Mauritius. International journal of quality and reliability management. 24(5):492-514.

38. Rohini R, Mahadevappa B. (2006). Service quality in Bangalore hospitals-an empirical study. Journal of services Research. $6(1): 59$.

39. Sadiq Sohail M. Service quality in hospitals: more favourable than you might think. Managing Service Quality: An International Journal. 2003 Jun 1;13(3):197-206.

40. Teas R.K.(1994). Expectations as a comparison standard in measuring service quality: an assessment of a reassessment. Journal of marketing. 58(1):132-9.

41. Wang Y, Lo H.P, Hui Y.V. (2003) The antecedents of service quality and product quality and their influences on bank reputation: evidence from the banking industry in China. Managing Service Quality: An International Journal. 1;13(1):72-83.

42. Wisniewski M. (2001).Using SERVQUAL to assess customer satisfaction with public sector services. Managing Service Quality: An International Journal. 11(6):380-8.

43. Woodruff R.B, Cadotte E.R, Jenkins R.L. (1983). Modeling consumer satisfaction processes using experience-based norms. Journal of marketing research. 3:296-304.

44. Yavas U, Bilgin Z, Shemwell D.J. (1997). Service quality in the banking sector in an emerging economy: a consumer survey. International Journal of Bank Marketing. 15(6):217-23. 